\title{
Management of type 2 diabetes: the current situation and key opportunities to improve care in the UK
}

Management of type 2 diabetes in the UK

S C Bain ${ }^{1}$, M Feher ${ }^{2}$, D Russell-Jones ${ }^{3,4}$, K Khunti ${ }^{5}$

${ }^{1}$ Institute of Life Sciences, University of Swansea, Swansea, UK

${ }^{2}$ Beta Cell Diabetes Centre, Chelsea and Westminster Hospital, London UK

${ }^{3}$ Centre for Endocrinology, Diabetes and Research, Royal Surrey County Hospital, Guildford, UK

${ }^{4}$ Diabetes and Metabolic Medicine, Faculty of Health and Medical Sciences, University of Surrey, Guildford, UK

${ }^{5}$ Diabetes Research Centre, University of Leicester, Leicester, UK

Corresponding author:

Professor Steve Bain

Telephone: (01792) 602205

Email: s.c.bain@swansea.ac.uk

Institute of Life Science, 3rd Floor, Singleton Park, Swansea, SA2 8PP

Word count: 4890 (including abstract)

Tables: 1

Figures: 4

References: 100

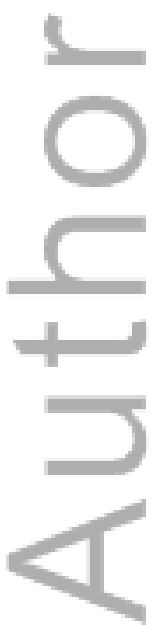

This is the author manuscript accepted for publication and has undergone full peer review but has not been through the copyediting, typesetting, pagination and proofreading process, which may lead to differences between this version and the Version of Record. Please cite this article as doi: 10.1111/dom.12760

This article is protected by copyright. All rights reserved. 


\section{Abstract}

In common with global trends, the number of individuals with Type 2 diabetes in the UK is rising, driven largely by obesity. The increasing prevalence of younger individuals with type 2 diabetes is of particular concern, due to the accelerated course of diabetes-related complications that is observed in this population. The importance of good glycaemic control in the prevention of microvascular complications of diabetes is widely accepted and there is a growing body of evidence to support a benefit in the reduction of cardiovascular events in the long-term. Despite the importance of maintaining a healthy weight for the prevention of type 2 diabetes; the results from trials of lifestyle intervention strategies to reduce body weight have been disappointing. New glucose-lowering agents offer some promise in this regard, offering an opportunity to combat the dual burden of hyperglycaemia and obesity simultaneously. The timing and appropriate choice of glucose lowering therapy has never been more complex owing to rising prevalence in the young, concomitant obesity in some $90 \%$ of adults with type 2 diabetes and an ever increasing range of therapeutic options. The present review evaluates performance measures specific to weight and glycaemic control in type 2 diabetes in the UK using data from the Quality and Outcomes Framework in England and Wales, and Scottish Diabetes Survey. Potential barriers to improvement in standards of care for people with type 2 diabetes are considered, including patient factors, clinical inertia and the difficulties in translating therapeutic guidelines into everyday clinical practice.

This article is protected by copyright. All rights reserved. 


\section{Introduction}

The publication of the updated National Institute for Health and Care Excellence (NICE) guidance for the management of type 2 diabetes [1] is a timely prompt to review opportunities to improve diabetes care. These guidelines have incorporated some recent therapeutic advances and have focused mainly on glycaemic indicators with regard to drug choices. By contrast the American Diabetes Association (ADA) [2] and International Diabetes Federation (IDF) [3] guidelines emphasise other factors to be considered in the choice of diabetes medicines in order to improve care. Due to the complexities of the condition, the range of drug classes to be considered, and patient and prescriber treatment considerations, the realities of clinical practice are indeed complex.

Efforts to curb the inevitable rise in complications associated with diabetes have led to a systematic evaluation of quality of care in England and Wales. Since 2004, disease specific indicators for both processes of care and treatment targets have been assessed through the pay for performance, Quality and Outcomes Framework (QOF). This review aims to evaluate contemporary care in the UK based on performance measures for glycaemic control and body-mass index. Particular emphasis will be placed on guidance from NICE that is most relevant to UK practice, and on which the QOF measures are based. In addition, barriers to "gold standard" care, and opportunities to improve existing standards, will be considered from a UK perspective.

\section{Importance of glycaemic control}

This article is protected by copyright. All rights reserved. 
There is established evidence confirming that improved blood glucose control results in substantial benefits in diabetes microvascular disease outcomes,[4-6] reducing disability in diabetes mediated by end organ damage to the eyes, kidneys and nerves. Diabetes is also associated with significant premature mortality, and around half of individuals with type 2 diabetes will die prematurely as a result of cardiovascular disease (CVD) [7]. The evidence for a reduction in CVD with intensive glucose control is less convincing when compared with microvascular outcomes. However, long-term follow-up among individuals with both type 1 [8] and type 2 diabetes $[9,10]$ randomised to strict glycaemic control has suggested that cardiovascular events are reduced when compared with standard treatment arms.

The 10-year extension post intervention in The UK Prospective Diabetes Study (UKPDS) reported a significant 15\% reduction in myocardial infarction (MI) and 13\% reduction in all-cause mortality among patients with type 2 diabetes receiving intensive therapy (sulphonylurea-insulin) compared to controls [9]. In the cohort of overweight patients receiving metformin, intensive therapy was associated with even greater reductions in the risk of $\mathrm{Ml}(33 \%)$ and death (27\%) [11]. At the conclusion of the interventional study, conventional treatment and intensive therapy corresponded with $\mathrm{HbA} 1 \mathrm{c}$ levels of $7.9 \%$ and $7.0 \%$, respectively. Importantly, the outcome benefits described above produced a legacy effect after a further 10-year extension, where no significant differences in glycaemic control were observed between study groups.

This article is protected by copyright. All rights reserved. 
In addition to glycaemic control, subsequent trials have evaluated other risk factors and shown that effective control of blood pressure and cholesterol in type 2 diabetes reduces rates of CVD and mortality $[12,13]$.

\section{Importance of weight control}

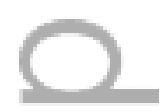

A recent report from Public Health England suggests that $90 \%$ of adults with type 2 diabetes are overweight or obese [14]. The relationship between BMI in type 2 diabetes and outcome has been extensively scrutinised. Reports of an obesity paradox in type 2 diabetes where raised BMI is associated with reduced mortality $[15,16]$ have been criticised for being underpowered or failing to adequately adjust for smoking history (associated with both reduced BMI and mortality). The obesity paradox was challenged by an analysis of pooled data from two large observational cohort studies including 11,427 patients with incident type 2 diabetes [17]. A direct linear relationship between mortality and BMI was observed among individuals who had never smoked and a J-shaped association among those with a history of smoking, where smoking attenuated the benefit of a low BMI. BMI data in this study were collected before, or shortly after, a diagnosis was made. A population-based cohort study in the UK supported the notion that both smoking and obesity contribute to the risk of all-cause mortality in type 2 diabetes. In this study a U-shaped curve associated with BMI and mortality was found; the hazard ratios for those with a BMI

of $35-54 \mathrm{~kg} / \mathrm{m} 2$ and $15-19 \mathrm{~kg} / \mathrm{m} 2$ were $1.43(1.28-1.59)$ and 1.38 (1.18-1.61), respectively (Figure 1) [18]. These data underscore the importance of maintaining a healthy body weight from the early stages of type 2 diabetes. 
Obese people are seven times more likely to develop type 2 diabetes compared to those with a healthy BMI $\left(20-25 \mathrm{~kg} / \mathrm{m}^{2}\right)$, with a threefold increased risk among those who are overweight [19]. Beyond incident type 2 diabetes, obesity is associated with other cardiovascular risk factors, including hypertension and, importantly, resistant hypertension [20,21]. Dietary interventions in the trial setting have yielded benefits in both the prevention of type 2 diabetes and improvement in glycaemic and blood pressure control among individuals with existing type 2 diabetes [22, 23]. Similarly, weight loss achieved through bariatric surgery has shown promise for patients with obesity and uncontrolled diabetes in terms of glycaemic control,[24] and metabolic changes observed postoperatively suggest there may be glycaemia benefits independent of weight loss per se [25].

The impact of lifestyle-mediated weight loss on cardiovascular outcomes in type 2 diabetes has also been investigated, most notably in the Look AHEAD study, which reported improved glycaemic control and CVD risk factor profile among participants randomised to intensive lifestyle intervention. This translated into clinically significant weight loss ( $8.6 \%$ of initial weight versus $0.7 \%$ among controls) at one year [26]. Despite sustained positive effects associated with intensive lifestyle intervention including the need for fewer glucose-lowering drugs and increased likelihood of achieving $\mathrm{HbA} 1 \mathrm{c}$ levels $<7 \%$ (53 $\mathrm{mmol} / \mathrm{mol}$ ) [27], the 10-year follow-up study showed no significant difference between groups for cardiovascular morbidity and mortality [28]. The spectrum of glucose lowering medications in type 2 diabetes includes those that promote weight gain (insulin, sulphonylureas and thiazolidinediones) and offer weight neutrality (metformin and dipeptidyl peptidase-4 inhibitors). The availability of novel agents associated with weight loss (glucagon-like peptide-1 receptor agonists 
and sodium-glucose co-transporter 2 inhibitors) offer promise for combatting obesity in type 2 diabetes as part of a multifactorial approach including good lifestyle.

\section{Economic considerations}

The burden of diabetes to the NHS is thought to represent around $5-10 \%$ of the overall budget and is projected to account for around 17\% in 2035 [29-31], with current direct costs attributable to type 2 diabetes estimated at around £8.8bn [31]. A health economics assessment undertaken by the York Health Economics Consortium suggests that less than a quarter of this cost relates to the treatment and ongoing management of diabetes; the remainder is attributable to the treatment of complications of the disease [31]. Because the effects of hyperglycaemia are cumulative [4, 11], it seems intuitive that early implementation of evidence based guidance and greater achievement of glycaemic and weight targets would reduce the incidence of complications or, at the very least delay their onset, resulting in cost savings for the health service. It is entirely paradoxical; therefore, to withhold best practice management early in the disease trajectory of type 2 diabetes in an effort to curb spending, as such practice is likely to increase the incidence of complications that account for a disproportionate share of overall healthcare costs. Early control of glycaemia in the decade following diagnosis, as observed in UKPDS, can mitigate risk of microvascular complications and has important legacy benefits for reduction of cardiovascular disease in the long-term [9].

Achievement of glycaemic (HbA1c) and BMI guideline targets on a population level 


\section{Glycaemic control}

An estimated 3.5 million individuals in the United Kingdom have type 2 diabetes [32], a figure that is expected to rise to over 5.5 million by 2035 [31], driven by population growth, ageing and rising levels of obesity. In the past two decades in the UK, the proportion of younger adults below the age of 40 with newly diagnosed type 2 diabetes has doubled [33]. Rising prevalence of young-onset diabetes will have a negative impact on the incidence of diabetes related complications as they are likely to develop at an earlier stage of life $[34,35]$, with implications for the individual and the health care authority in which they reside. Among individuals with type 2 diabetes in youth, higher $\mathrm{HbA1c}$ is associated with greater risk of complications [36], reinforcing the importance of optimising glycaemic control early on in the natural history of disease.

The 2015 NICE guidance recommends an $\mathrm{HbA} 1 \mathrm{c}$ target of $48 \mathrm{mmol} / \mathrm{mol}(6.5 \%)$ for individuals with type 2 diabetes managed by lifestyle and a single glucose-lowering agent (Table 1) [1]. Additional or add-on therapy is advocated when $\mathrm{HbA} 1 \mathrm{c}$ rises to $58 \mathrm{mmol} / \mathrm{mol}(7.5 \%)$ or higher with intensified monotherapy and reinforced lifestyle advice. At this junction, the target $\mathrm{HbA} 1 \mathrm{c}$ is increased to $53 \mathrm{mmol} / \mathrm{mol}(7.0 \%)$. The UK National Diabetes Audit measures the effectiveness of diabetes care in England and Wales against NICE standards. In the most recent audit year (2014-2015), around 4700 primary care practices and 99 specialised services contributed data on 1.9 million individuals with diabetes [37]. Between 2009 and 2015, between 90 and $95 \%$ of patients with $\mathrm{T} 2 \mathrm{DM}$ underwent $\mathrm{HbA} 1 \mathrm{c}$ monitoring at 6 monthly intervals, of 
whom 65 to $67 \%$ achieved NICE treatment targets (applicable to that period) of $\leq 58$ $\mathrm{mmol} / \mathrm{mol}(7.5 \%)$ (Figure 2). Significantly, the lowest rates of achievement were among patients under 40 years and those aged 40 to 64 years, and appreciable geographical variation in achievement of treatment targets was observed.

In Scotland during the same time period, achievement of the NICE target $\leq 58$ $\mathrm{mmol} / \mathrm{mol}(7.5 \%)$ ranged from 60 to $64 \%$. Between $13 \%$ and $15 \%$ of those with type 2 diabetes in Scotland had an $\mathrm{HbA} 1 \mathrm{c}>75 \mathrm{mmol} / \mathrm{mol}(9.0 \%)$ [38]. This statistic is alarming given that UKPDS reported MI event rates of 20 per 1000 person years among participants with an $\mathrm{HbA} 1 \mathrm{c}$ between 9.0 and $10.0 \%$ compared to 13 per 1000 person years among those with good glycaemic control (HbA1c 6.0-7.0\%) [39]. In that study, for each $1 \%$ reduction in $\mathrm{HbA} 1 \mathrm{c}$ events rates were reduced significantly for diabetes-related deaths $(21 \%)$, myocardial infarction $(14 \%)$ and microvascular complications (37\%). It is also significant that no lower $\mathrm{HbA} 1 \mathrm{c}$ threshold for risk was observed for any endpoint (Figure 3).

\section{International comparisons}

r.

UK data on achievement of $\mathrm{HbA} 1 \mathrm{c}$ goals can be compared with the most recent reports based on the National Health and Nutrition Examination Survey in the US, where, between 2007 and 2010, 52.2\% and $79.1 \%$ of participants had an $\mathrm{HbA} 1 \mathrm{c}<53$ $\mathrm{mmol} / \mathrm{mol}(7.0 \%)$ and $<64 \mathrm{mmol} / \mathrm{mol}(8.0 \%)$, respectively [40]. Among patients in the Swedish National Diabetes Register with type 2 diabetes and no history of coronary heart disease, $78.4 \%$ achieved national guideline targets of an $\mathrm{HbA} 1 \mathrm{c}<56 \mathrm{mmol} / \mathrm{mol}$ $(7.3 \%)$ in 2008 [41]. Although not a directly comparable cohort, these European data 
would suggest that UK achievement of glycaemic goals are not among the best in Europe. The European Study on Cardiovascular Risk Prevention and Management in Usual Daily Practice (EURIKA) that collected data between 2009 and 2010 suggested wide variation in achievement of glycaemic goals across European countries. Among 2046 patients with type 2 diabetes, an $\mathrm{HbA} 1 \mathrm{c}$ of $<48 \mathrm{mmol} / \mathrm{mol}$ $(6.5 \%)$ was achieved in $36.7 \%$, and varied between $26.0 \%$ and $48.4 \%$ between the 12 countries that contributed patients, although numbers in each were small [42]. A report from the Guideline Adherence to Enhance Care (GUIDANCE) study conducted across 8 European countries in primary and specialist care found only $53.6 \%$ of participants had an $\mathrm{HbA} 1 \mathrm{c}<53 \mathrm{mmol} / \mathrm{mol}(7.0 \%)$, again with a lack of between-country consistency in achievement of targets [43].

Weight (BMI) control

Body-mass index was also well recorded in both England and Wales, and Scotland. From 2009, a record of BMI was made in between 82.0 and $89.7 \%$ of individuals with type 2 diabetes in Scotland [38], and 83.1 to $90.9 \%$ in England and Wales [32]. The BMI data for Scotland in 2014 suggest that $87 \%$ of patients with type 2 diabetes were overweight or obese $\left(\mathrm{BMI} \geq 25 \mathrm{~kg} / \mathrm{m}^{2}\right)$, over half of patients satisfied BMI criteria for obesity $\left(\geq 30 \mathrm{~kg} / \mathrm{m}^{2}\right)$ and $26 \%$ of patients had severe obesity $\left(\mathrm{BMI} \geq 35 \mathrm{~kg} / \mathrm{m}^{2}\right.$ ). Similarly, in 2009-2010 in England and Wales, 90\% of adults with type 2 diabetes aged 15-54 years were overweight or obese. Consistent with findings of inferior glycaemic control in younger people with type 2 diabetes in the National Diabetes Audit, the proportion with overweight or obesity was greater among individuals aged 16-54 years than those 55 years or older (Figure 4) [44].

This article is protected by copyright. All rights reserved. 


\section{Barriers to optimal care and opportunities for improvement}

The overall benefit of improved glycaemic control and weight reduction in type 2 diabetes has been demonstrated definitively [45-47], yet achievement of targets on a population level remains poor. Suboptimal treatment and control of type 2 diabetes is a multifactorial issue, and the success of any strategy to overcome it will be predicated on an understanding of the progressive natural history of the disease and the ability to overcome a number of practical barriers. The progressive nature of type 2 diabetes means an escalation of treatment is usual in order to improve glycaemic control and reduce complications [48]. A "one size fits all" approach is unlikely to be effective because disease progression results from a combination of impaired insulin sensitivity and beta-cell dysfunction that vary on an individual basis. Additionally there is a wide range in patient responses to the different drugs and drug classes used in diabetes [49]. The result of inadequate response to single therapy is often a complex prescribing pattern, which has implications for patients and physicians. The complexity of treatment regimen is inversely associated with adherence and [50,51], in turn, poor adherence is associated with smaller reductions in HbA1c [52]. For physicians, interpreting and implementing clinical guidelines in the context of an individual patient can be a daunting prospect, further complicated by the wide range of treatment regimens now available.

\section{Adherence issues}

This article is protected by copyright. All rights reserved. 
The World Health Organisation recognise patient non-adherence to therapies as one of the major barriers to improving health outcomes [53], and there are UK-based data to support this view in type 2 diabetes. An analysis of primary care records, that were adjusted for confounding factors found that non-adherence to prescribed medications and clinic non-attendance were independent risk factors for death from any cause among individuals with type 2 diabetes [54]. Barriers to adherence can result from a multiplicity of factors including polypharmacy, complexity of medication regimens, tolerability of medications including side effects such as gastrointestinal disturbance, weight gain and hypoglycaemia, poor knowledge of disease and cognitive impairment among elderly patients. Modifications to reduce the frequency of administration or the number of therapies are likely to improve compliance, and the role of fixed-dose combinations or co-administered dual therapy with reduced pill burden is likely to expand in this regard [55]. Reasons for non-adherence may change during the course of disease, but adherence is most likely to decline in the first six months following initiation of therapy [56]. This finding has implications for starting de-novo drug treatment and escalating therapy. A report evaluating participants with type 2 diabetes newly started on a first antihyperglycaemic treatment suggests poor medication adherence was associated with elevated $\mathrm{HbA} 1 \mathrm{c}$ and predicted delay to intensification of therapy [57]. Patients in the highest adherence quartile were significantly more likely to have their regimens intensified during at least three years of follow up than those in the lowest quartile for adherence (37.4\% versus $26.7 \%)$.

Patient factors

This article is protected by copyright. All rights reserved. 
Fear of weight gain or hypoglycaemia, whether real or perceived, can negatively influence adherence to medication [58, 59]. Furthermore, individuals who are obese have been shown to have significantly poorer adherence than their non-obese counterparts with type 2 diabetes [60]. Many glucose lowering treatments are known to drive weight gain and observational data from the UK suggest that weight gain after initiating a new glucose-lowering therapy is associated with increasing primary care spending that results from both increased prescribing and contact with primary care physicians [61]. Such barriers may be overcome with the availability of glucoselowering therapies that offer weight neutrality or reduction, and those with reduced incidence of hypoglycaemia, although the benefits of these agents for adherence will rely on patient awareness. Where agents can successfully combine efficacy in $\mathrm{HbA} 1 \mathrm{c}$ reductions and weight loss, as has been demonstrated in real world data on SGLT2 inhibitors and GLP-1 receptor agonists [62, 63], patients may gain positive reinforcement to maintain good adherence and improve lifestyle choices to promote further weight loss.

\section{Patient education}

Patient education remains a foundation of existing type 2 diabetes programmes and is a widely recommended strategy to improve outcome [64]. While it is indisputable that patient knowledge is important for several aspects of care, there are few trial data to support the efficacy of this approach for improvement in glycaemic control. A meta-analysis of 18 randomised controlled trials evaluating the effect of educational interventions on body weight and glycaemic control in type 2 diabetes reported pooled reductions in $\mathrm{HbA} 1 \mathrm{c}$ of $0.4 \%$, compared with control arms [65]. A more recent 
study evaluating the effectiveness of a group-based self management (X-PERT) programme in the UK also demonstrated modest improvements in HbA1c $(-0.6 \%)$ when compared to a control group with type 2 diabetes attending individual appointments [66]. Participation was also associated with improvement in BMI ($0.2 \mathrm{~kg} / \mathrm{m}^{2}$ vs $+0.4 \mathrm{~kg} / \mathrm{m}^{2}$ ) and waist circumference at 14 months. Assessment of the diabetes education and self-management programme (DESMOND) in 731 individuals with newly diagnosed type 2 diabetes, at 207 general practices in the UK, failed to demonstrate any benefit in $\mathrm{HbA} 1 \mathrm{c}$ control in comparison with controls at three years [67]. Beyond the controlled trial setting, evidence is currently lacking to support long-term benefits of structured education.

In the same way that diabetes management is increasingly tailored to a specific patient profile, the solutions to poor adherence should also be personalised. The patient-healthcare provider relationship is central to the solution and should aim to build trust and a greater understanding of the disease and treatment options. The majority of diabetes is self-managed and patients must "buy in to" a strategy to prolong healthy life and reduce the risks of complications.

\section{Clinical inertia}

Clinical inertia has been defined as a failure to intensify treatment on a timely basis despite inadequate treatment response. It is a phenomenon common to several major chronic diseases including hypertension and dyslipidaemia, as well as diabetes. This difficulty in translating evidence based guidance on escalation of treatment into practice has been attributed to barriers at the healthcare system, 
healthcare provider and patient level $[68,69]$. The magnitude of the problem is highlighted by the statistic that less than two thirds of patients in the UK are achieving even modest $\mathrm{HbA} 1 \mathrm{c}$ targets of $\leq 58 \mathrm{mmol} / \mathrm{mol}(7.5 \%)$, as previously discussed. A study by Khunti et al using administrative care data on over 80,000 individuals with type 2 diabetes in UK primary care suggests there are significant delays in treatment intensification following sup-optimal HbA1c control [70]. The mean $\mathrm{HbA} 1 \mathrm{c}$ level at which escalation of treatment occurred was $8.7,9.1$ and $9.7 \%$ among individuals taking one, two or three oral antihyperglycaemic medications, respectively. Furthermore the median time to starting a second-line treatment for those poorly controlled $(\mathrm{HbA} 1 \mathrm{c}>7 \%)$ on monotherapy was 2.9 years. A further UKbased study reported a mean gap of 7.7 years from initiation of a second or third line oral antihyperglycaemic agent and insulin therapy, with a mean $\mathrm{HbA} 1 \mathrm{c}$ of around $10 \%(86 \mathrm{mmol} / \mathrm{mol})$ at the time of first insulin prescription [71]. Data from controlled trials indicating improvement in these outcomes translates into meaningful reductions in diabetes-related complications has been replicated in "real-world" data. A study involving over 100,000 patients registered at a general practice in the UK found the risk of cardiovascular events is increased when treatment escalation is delayed [72].

Given the wealth of available treatment algorithms for type 2 diabetes and the apparent lack of adherence to them in many cases, much of the emphasis has been placed on physician behaviour and education in efforts to overcome inertia and improve care [73-75]. This is, however, a simplistic view because physician inertia may also be influenced by patient-related and systematic factors [76-78]. For their part, health care professionals should aim to detect problems early, set realistic goals and promptly intervene [79]. These steps are reliant on a sound understanding of the 
available treatment options and their implementation will have significant overlap with systemic factors in the healthcare system in which they practice.

\section{Translating guidelines into clinical practice}

The introduction of incentivised payments in 2004 through QOF has arguably been the most significant systematic effort to drive standards in diabetes care in the UK. A systematic review of studies published between 1999 and 2006 found that the introduction of QOF incentives has led to significant improvements in both standards of care and major intermediary outcome measures including $\mathrm{HbA} 1 \mathrm{c}$ [80]. These data are supported by a more recent study of routine administrative health data from practices in England which showed stepwise improvements in the proportion of patients achieving target $\mathrm{HbA} 1 \mathrm{c}$ of $\leq 7.5 \%$ (59.1\% in $2004-2005$ versus $80.2 \%$ in 2007-2008 [81]. The QOF revision in 2011/2012 that raised the threshold at which the $\mathrm{HbA} 1 \mathrm{c}$ indicator was incentivised, from $53 \mathrm{mmol} / \mathrm{L}(7 \%)$ to $58 \mathrm{mmol} / \mathrm{L}(7.5 \%)$ may have served to increase clinical inertia around escalation of antihyperglycaemic therapy. Indeed, the proportion of patients achieving an $\mathrm{HbA} 1 \mathrm{c}$ goal of $<7.5 \%$ in England and Wales has never reached the levels of 2010/2011 since that year (Figure 2).

Despite the overall positive influence of QOF incentives on routine monitoring, and modest improvements in glycaemic control that have resulted, the trend for increased chronic disease management in primary care and away from disease specialists has placed pressure on providers in terms of length and frequency of appointments, and the levels of knowledge expected of them. Contemporary guidelines have done little 
to simplify the complexity and volume of research on glucose lowering agents [1, 2], such that they may be difficult to interpret for the specialist, let alone a primary health care provider who must be familiar with the management of several chronic diseases. The flow diagrams featured in recent NICE guidance are hard to follow and fail to provide clear recommendations for commonly encountered patient subgroups [82]. When simple and accessible, use of glucose algorithms at the point of care has been shown to improve physician behaviour as measured by frequency of intensification, with subsequent improvements in glycaemic control [83]. There are clear roles for treatment algorithms in diabetes, as these process of care interventions have also been shown to reduce clinical inertia in other areas of medicine [84]; however, they must be accessible to the primary care providers who undertake the lions share of diabetes management in the UK.

\section{Timing and selection of add-on therapy}

There exists near universal acceptance that metformin should remain the first-line therapy among individuals in whom lifestyle modification is insufficient to control hyperglycaemia [1, 2, 64]. There is still a debate surrounding the selection of a second-line agent when metformin monotherapy fails to adequately control hyperglycaemia. It is here that the drive to individualise therapy is most relevant and the reason behind the complexity of many consensus guidelines. In the 2015 joint treatment guidelines from the European EASD and North American ADA, there are

six drug classes to choose from when advancing to dual combination therapy, including sulfonylureas (SU), thiazolidinediones (TZD), dipeptidyl peptidase-4 (DPP4) inhibitors, GLP-1 agonists, sodium-glucose cotransporter 2 (SGLT2) inhibitors and 
insulin. The EASD/ADA position statement acknowledges that initial combination therapy with metformin and a second-line agent may help patients to reach target $\mathrm{HbA1c}$ quicker than sequential therapy, particularly among individuals with very high baseline values [2], a position echoed by the American College of Endocrinologists for individuals with a baseline $\mathrm{HbA} 1 \mathrm{c}>7.5 \%$ [85]. This recommendation is welcome for the reasons outlined above and contrasts slightly with those of the recent NICE document which provides a different message by its suggestion of waiting until $\mathrm{HbA} 1 \mathrm{c}$ rises to $>58 \mathrm{mmol} / \mathrm{mol}(7.5 \%)$ before escalation of therapy [1].

Sulfonylureas, with 60 years of clinical data, have been a mainstay of add-on therapy in type 2 diabetes and their combination with metformin has served as a control in several trials of newer agents. In a UK study using primary care data on over 25,000 individuals with type 2 diabetes, TZDs and DPP-4 inhibitors demonstrated near equivalent glucose lowering effects to SUs when combined with metformin [86]. There are some data to support greater $\mathrm{HbA} 1 \mathrm{c}$ lowering with the combination of GLP-1 receptor agonists with metformin over combinations with a DPP-4 inhibitor [87], although other combinations with SUs and TZDs are broadly equivalent in their glucose lowering effects. The newest class of agent, SGLT2 inhibitors, have fewer data on comparative effectiveness but appear to offer similar efficacy to other agents, leading to $\mathrm{HbA} 1 \mathrm{c}$ reductions $\approx 0.5-1.0 \%[88,89]$. Pooled data from regulatory submissions and published trials suggest that SGLT2 inhibitors offer a magnitude of cardiovascular protection greater than might be expected by reductions in $\mathrm{HbA} 1 \mathrm{C}$ alone [90, 91]. SGLT2 inhibitors work uniquely to lower the renal threshold for glucose, which is excreted at greater concentrations in the urine, leading to both lowering of blood glucose and reductions in weight owing to caloric loss. This class of 
antihyperglycaemics are likely to have the greatest role early in the disease course relative to other add-on therapies given that renal excretion of glucose with SGLT2 inhibitors will be attenuated with declining eGFR, which is progressive in type 2 diabetes [92, 93], and data to suggest they offer a longer duration of glucose lowering effect when compared to SUs [94], and on indirect comparison with the literature on DPP-4 inhibitors [95]. GLP-1 receptor agonists are the other class of glucose lowering drugs that promote weight loss, and there are early data to support reductions in cardiovascular events with these agents also [96]. They act on pancreatic islet cells to stimulate insulin secretion and inhibit glucagon secretion, while also delaying gastric emptying and promoting satiety, hence their propensity to promote weight loss. Real world data from the UK suggest that GLP-1 receptor agonists can offer greater reductions in $\mathrm{HbA} 1 \mathrm{c}$ and improved weight control when compared to DPP-4 inhibitors [97], a finding that is supported by some trial evidence [98].

Comparative effectiveness data from the Glycemia Reduction Approaches in Diabetes: A Comparative Effectiveness Study (GRADE) that is expected to report in 2020 will provide much needed long-term data on available medications when added on to metformin [99]. The study will randomise 5000 participants to combination therapy with metformin and one of four agents: glimepiride, sitagliptin, liraglutide or insulin glargine; unfortunately the trial does not include an SGLT2 inhibitor arm. The primary endpoint has been confirmed as the time to failure of glycaemic control that is defined as an $\mathrm{HbA} 1 \mathrm{c}$ of $7.0 \%$ or higher. Although secondary outcomes with respect to hypoglycaemic episodes, weight, microvascular disease and 
cardiovascular risk factors will be monitored, the trial is primarily designed to address which agent provides the best long-term control of blood glucose.

\section{Conclusions}

Good glycaemic control is the cornerstone of any strategy to reduce the risk of diabetes-related complications, yet achievement of evidence based guideline targets in the UK is modest at best. While incentivised payments in primary practice have driven standards of care with respect to identifying poor HbA1c control in type 2 diabetes, this modifiable risk is not being addressed in a timely fashion. The reasons for this are complex and multifactorial, involving healthcare system, physician and patient factors. Efforts to address suboptimal care in the UK should involve an emphasis shift from the management of complications to their prevention, a move that will have enormous health and economic implications for the better. Key opportunities lie in the appropriate selection of therapies for the majority of people with type 2 diabetes who are overweight or obese, optimising the timing of add-on therapies and finally, addressing issues of patient adherence.

\section{Conflict of Interest}

SB has attended advisory panels for AstraZeneca, Boehringer Ingelheim, BristolMyers Squibb, Janssen, Eli Lilly \& Co, Merck Sharp \& Dohme, Novo Nordisk, OmniaMed, and Sanofi; and is a board member for Glycosmedia. MF has received financial support for research, speaker meetings and consultancy from pharmaceutical companies Merck Sharpe and Dohme, Merck, AstraZeneca, Pfizer, 
Sanofi, Novo Nordisk, Eli Lilly, and Boehringer Ingelheim. DRJ has received research funding or advisory board or lecture fee honoraria from Novo Nordisk. KK is a member of the National Institute for Health and Clinical Excellence public health guidance on preventing type 2 diabetes and an adviser to the UK Department of Health for the NHS health checks programme.

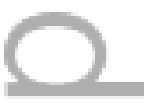

\section{Acknowledgements}

The authors thank Tom Shakespeare of Spotlight Research Ltd, who provided medical editorial assistance. Funding for medical editorial support was provided by AstraZeneca UK Limited.

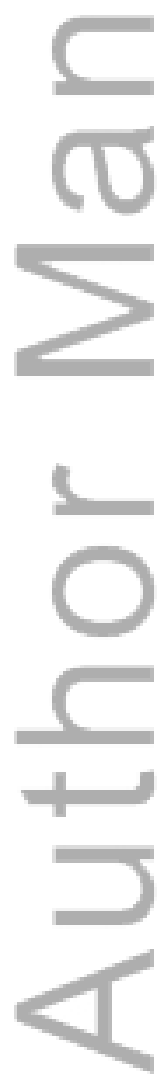

This article is protected by copyright. All rights reserved. 
Table 1. Summary of NICE and EASD guidelines for glycaemic ( $\mathrm{HbA1c})$ control in type 2 diabetes [2, 64, 82, 100]

\begin{tabular}{|c|c|c|}
\hline Guideline & Cohort & $\begin{array}{l}\text { HbA1c target } \\
\text { mmol (\%) }\end{array}$ \\
\hline $\begin{array}{l}\text { NICE CG } 87 \\
(2009)[100]\end{array}$ & T2DM general target & $\begin{array}{c}48 \mathrm{mmol} / \mathrm{mol} \\
(6.5 \%)\end{array}$ \\
\hline \multirow[t]{3}{*}{$\begin{array}{l}\text { NICE NG 28 } \\
(2015)[1]^{\dagger}\end{array}$} & $\begin{array}{l}\text { T2DM managed by lifestyle and diet }+/- \text { single } \\
\text { drug }\end{array}$ & $\begin{array}{l}48 \mathrm{mmol} / \mathrm{mol} \\
(6.5 \%)\end{array}$ \\
\hline & $\begin{array}{l}\text { T2DM, if HbA1c level not adequately controlled } \\
\text { by a single drug and rise to } 58 \mathrm{mmol} / \mathrm{mol} \\
(7.5 \%) \text { or higher }\end{array}$ & $\begin{array}{c}53 \mathrm{mmol} / \mathrm{mol} \\
(7.0 \%)^{*}\end{array}$ \\
\hline & $\begin{array}{l}\text { T2DM, on a drug associated with } \\
\text { hypoglycaemia }\end{array}$ & $\begin{array}{l}53 \mathrm{mmol} / \mathrm{mol} \\
(7.0 \%)\end{array}$ \\
\hline \multirow{3}{*}{$\begin{array}{l}\text { EASD / ADA } \\
\text { position statement } \\
2012 \text { (update } \\
2015)[2,64]\end{array}$} & T2DM general target & $\begin{array}{c}<53 \mathrm{mmol} / \mathrm{mol} \\
(7.0 \%)\end{array}$ \\
\hline & $\begin{array}{l}\text { Selected patients with short disease duration, } \\
\text { long life expectancy, no CV risk factors }\end{array}$ & $\begin{array}{l}42-48 \mathrm{mmol} / \mathrm{mol} \\
(6.0-6.5 \%)\end{array}$ \\
\hline & $\begin{array}{l}\text { Selected patients with severe hypoglycaemia, } \\
\text { limited life expectancy, advanced } \\
\text { complications, extensive comorbidity }\end{array}$ & $\begin{array}{c}58-64 \mathrm{mmol} / \mathrm{mol} \\
(7.5-8.0 \%)\end{array}$ \\
\hline
\end{tabular}

* Intensify drug treatment

${ }^{\dagger}$ Consider relaxing all above, on case-by-case basis, for older and frail patients with multiple comorbidities.

This article is protected by copyright. All rights reserved. 


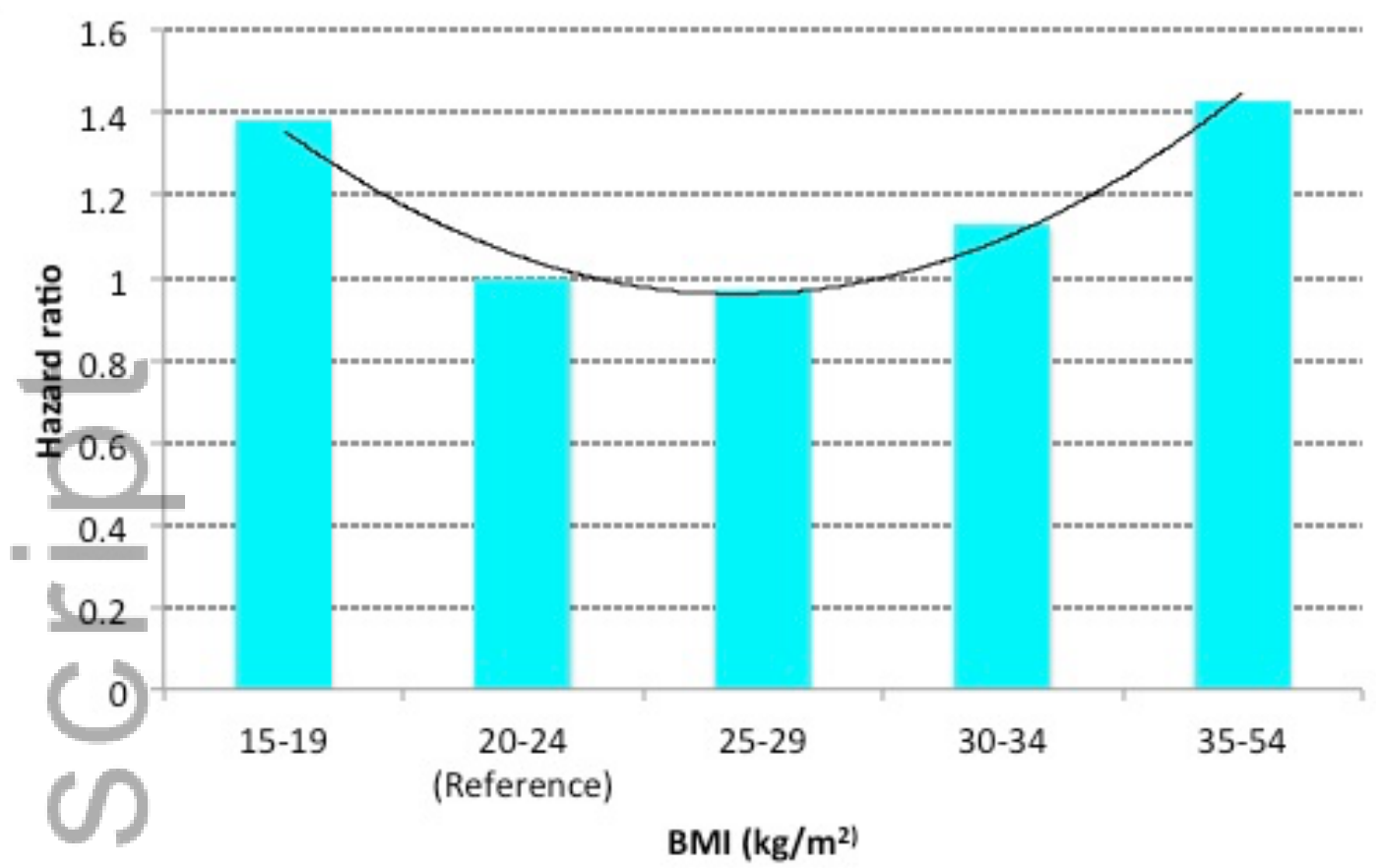

Figure 1. The association of BMI and all-cause mortality in type 2 diabetes

Adjusted for age, gender, smoking status and duration of diabetes Adapted from Mulnier et al[18]

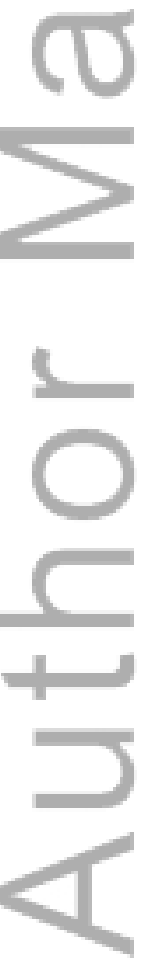

This article is protected by copyright. All rights reserved. 


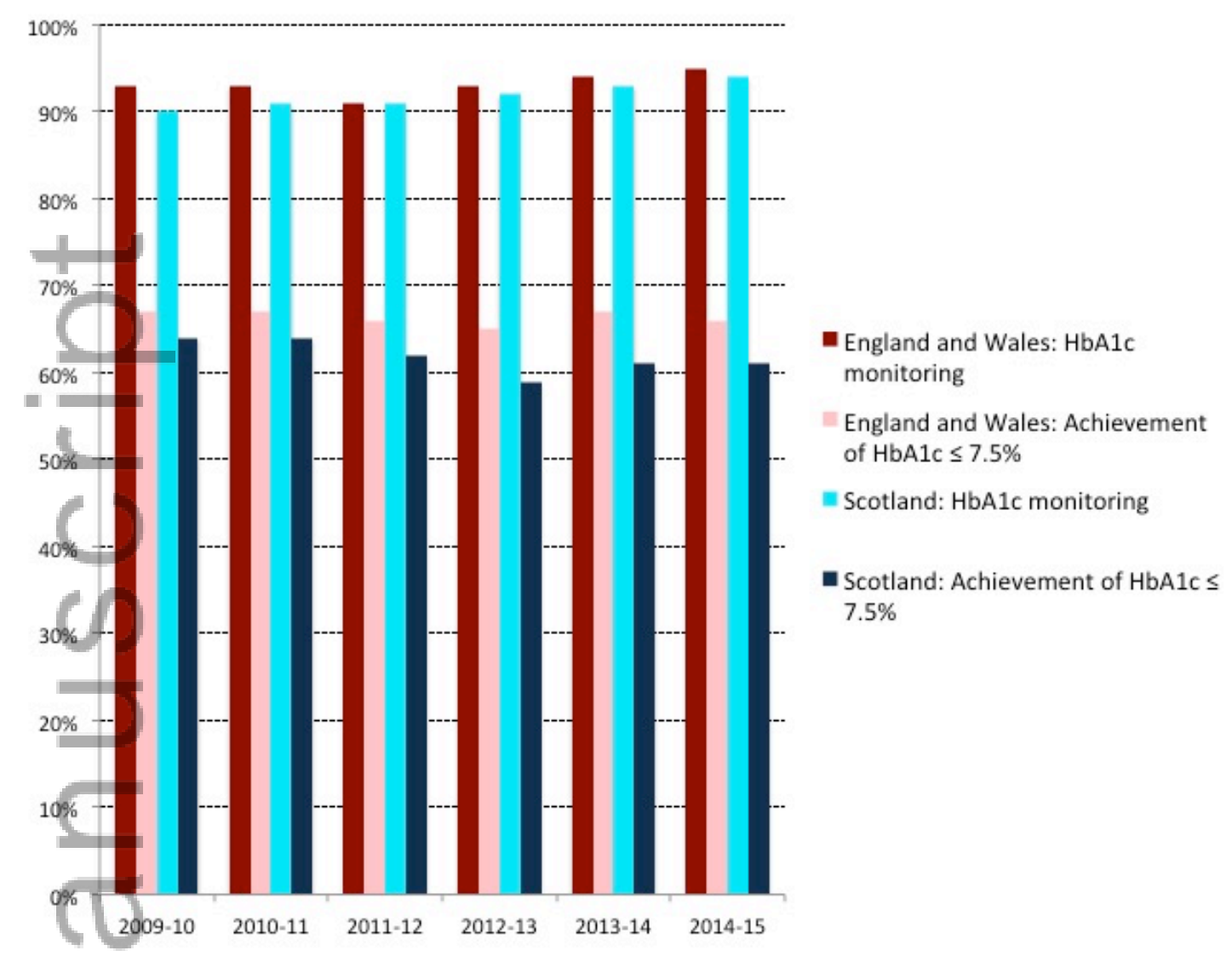

Figure 2. Percentage achievement of NICE recommended $\mathrm{HbA} 1 \mathrm{c}$ monitoring and treatment targets $(\leq 58 \mathrm{mmol} / \mathrm{mol})$ among individuals with type 2 diabetes in England, Wales and Scotland[1, 37, 38]

*Data provided for type 1 and type 2 diabetes combined

2
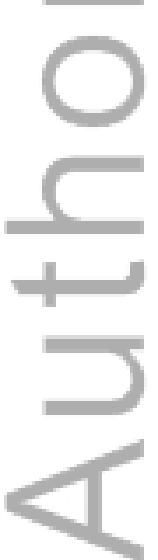

This article is protected by copyright. All rights reserved. 


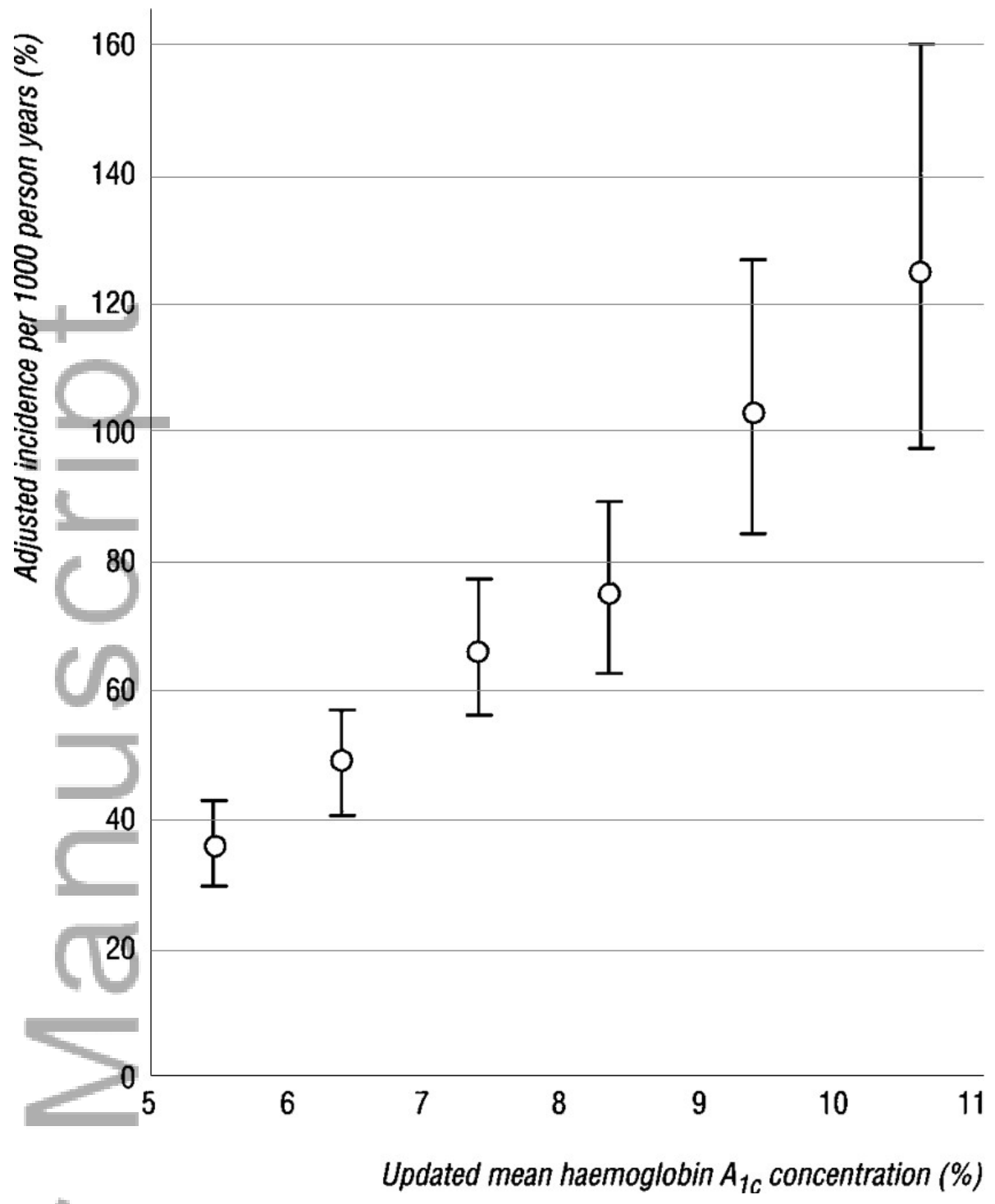

Figure 3. Endpoint related to diabetes: adjusted incidence rate and $95 \%$ confidence intervals for any endpoint related to diabetes by category of $\mathrm{HbA} 1 \mathrm{c}^{*}$

*Endpoint includes myocardial infarction, sudden death, angina, stroke, renal failure, lower extremity amputation or death from peripheral vascular disease, death from hyperglycaemia or hypoglycaemia, heart failure, vitreous haemorrhage, retinal photocoagulation, and cataract extraction

Taken from Stratton et al, UKPDS 35[39]

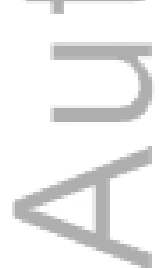

This article is protected by copyright. All rights reserved. 


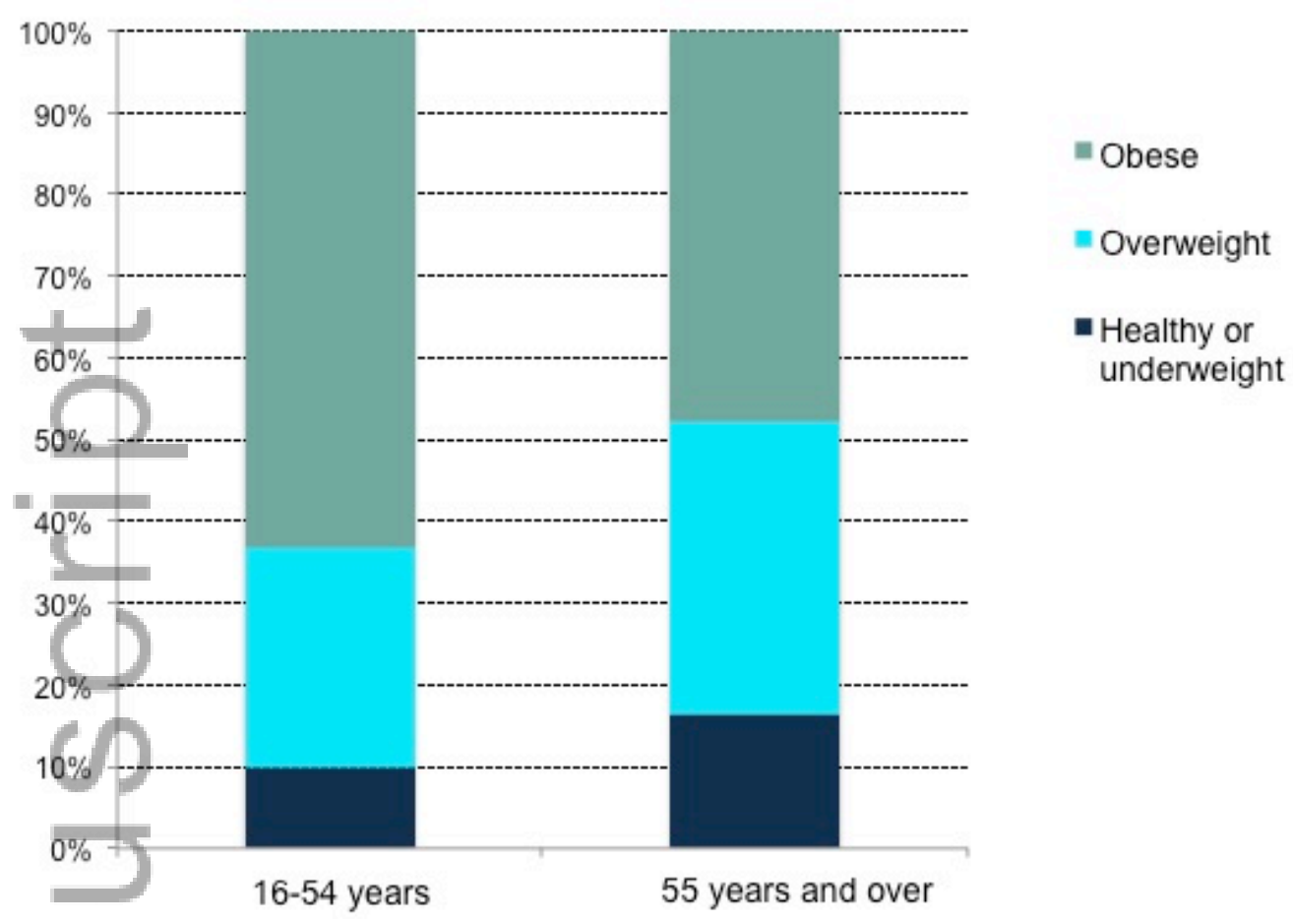

Figure 4. Weight status among adults with type 2 diabetes in England and Wales Extrapolated from data provided by the National Diabetes Audit 2009-2010[44]
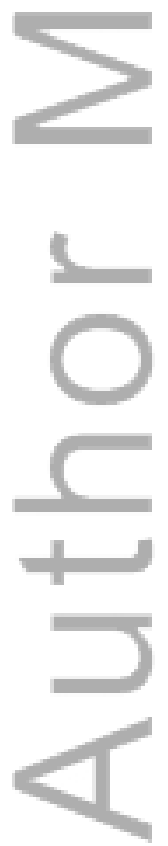

This article is protected by copyright. All rights reserved. 


\section{References}

[1] Type 2 diabetes in adults: management. NICE guideline 28, 2015

[2] Inzucchi SE, Bergenstal RM, Buse JB, et al. Management of hyperglycaemia in type 2 diabetes, 2015: a patient-centred approach. Update to a position statement of the American Diabetes Association and the European Association for the Study of Diabetes. Diabetologia 2015; 58: 429-442

[3] Group IDFGD. Global guideline for type 2 diabetes. Diabetes Res Clin Pr 2014; 104: 1

[4] Group UPDS. Intensive blood-glucose control with sulphonylureas or insulin compared with conventional treatment and risk of complications in patients with type 2 diabetes (UKPDS 33). Lancet 1998; 352: 837-853

[5] Patel A, MacMahon S, Chalmers J, et al. Intensive blood glucose control and vascular outcomes in patients with type 2 diabetes. New Engl J Med 2008: [6] Boussageon R, Bejan-Angoulvant T, Saadatian-Elahi M, et al. Effect of intensive glucose lowering treatment on all cause mortality, cardiovascular death, and microvascular events in type 2 diabetes: meta-analysis of randomised controlled trials. BMJ 2011; 343: d4169

[7] Seshasai SRK, Kaptoge S, Thompson A, et al. Diabetes mellitus, fasting glucose, and risk of cause-specific death. New Engl J Med 2011; 364: 829 [8] Control D, Trial C. Intensive diabetes treatment and cardiovascular disease in patients with type 1 diabetes. New Engl J Med 2005; 353: 2643 [9] Holman RR, Paul SK, Bethel MA, Matthews DR, Neil HA. 10-year follow-up of intensive glucose control in type 2 diabetes. N Engl J Med 2008; 359: 15771589

[10] Hayward RA, Reaven PD, Wiitala WL, et al. Follow-up of glycemic control and cardiovascular outcomes in type 2 diabetes. New Engl J Med 2015; 372: 2197-2206

[11] Group UPDS. Effect of intensive blood-glucose control with metformin on complications in overweight patients with type 2 diabetes (UKPDS 34). Lancet 1998; 352: 854-865

[12] Kearney P, Blackwell L, Collins R, et al. Efficacy of cholesterol-lowering therapy in 18,686 people with diabetes in 14 randomised trials of statins: a meta-analysis. Lancet 2008; 371: 117-125

[13] Group UPDS. Tight blood pressure control and risk of macrovascular and microvascular complications in type 2 diabetes: UKPDS 38. BMJ 1998: 703-713 [14] Adult obesity and type 2 diabetes. Public Health England, 2014 [15] Carnethon MR, De Chavez PJD, Biggs ML, et al. Association of weight status with mortality in adults with incident diabetes. JAMA 2012; 308: 581-590 [16] Logue J, Walker JJ, Leese G, et al. Association between BMI measured within a year after diagnosis of type 2 diabetes and mortality. Diabetes Care 2013; 36: 887-893

[17] Tobias DK, Pan A, Jackson CL, et al. Body-mass index and mortality among adults with incident type 2 diabetes. New Engl J Med 2014; 370: 233-244 
[18] Mulnier H, Seaman H, Raleigh V, Soedamah - Muthu S, Colhoun H, Lawrenson R. Mortality in people with type 2 diabetes in the UK. Diabetic Med 2006; 23: 516-521

[19] Abdullah A, Peeters A, De Courten M, Stoelwinder J. The magnitude of association between overweight and obesity and the risk of diabetes: a metaanalysis of prospective cohort studies. Diabetes Res Clin Pr 2010; 89: 309-319 [20] Lloyd-Jones DM, Evans JC, Larson MG, O’Donnell CJ, Roccella EJ, Levy D. Differential control of systolic and diastolic blood pressure factors associated with lack of blood pressure control in the community. Hypertension 2000; 36: 594-599

[21] Bramlage P, Pittrow D, Wittchen $\mathrm{H}-\mathrm{U}$, et al. Hypertension in overweight and obese primary care patients is highly prevalent and poorly controlled. Am J Hyperten 2004; 17: 904-910

[22] Liese AD, Nichols M, Sun X, D'Agostino RB, Haffner SM. Adherence to the DASH Diet is inversely associated with incidence of type 2 diabetes: the insulin resistance atherosclerosis study. Diabetes Care 2009; 32: 1434-1436

[23] Azadbakht L, Fard NRP, Karimi M, et al. Effects of the dietary approaches to stop hypertension (DASH) eating plan on cardiovascular risks among type 2

diabetic patients a randomized crossover clinical trial. Diabetes Care 2011; 34: 55-57

[24] Schauer PR, Kashyap SR, Wolski K, et al. Bariatric surgery versus intensive medical therapy in obese patients with diabetes. New Engl J Med 2012; 366: 1567-1576

[25] Mingrone G, Castagneto-Gissey L. Mechanisms of early improvement/resolution of type 2 diabetes after bariatric surgery. Diabetes Metab 2009; 35: 518-523

[26] Espeland M. Reduction in weight and cardiovascular disease risk factors in individuals with type 2 diabetes: one-year results of the look AHEAD trial. Diabetes Care 2007:

[27] Group LAR. Long term effects of a lifestyle intervention on weight and cardiovascular risk factors in individuals with type 2 diabetes: four year results of the Look AHEAD trial. Arch Int Med 2010; 170: 1566

[28] Group LAR. Cardiovascular effects of intensive lifestyle intervention in type 2 diabetes. New Engl J Med 2013; 369: 145

[29] Observatory. YaHPH. Diabetes Key Facts: York: Yorkshire and Humber Public Health Observatory., 2006

[30] Turning the corner: improving diabetes care.: London: Department of Health, 2006

[31] Hex N, Bartlett C, Wright D, Taylor M, Varley D. Estimating the current and future costs of Type 1 and Type 2 diabetes in the UK, including direct health costs and indirect societal and productivity costs. Diabetic Med 2012; 29: 855862 
[32] Quality and Outcomes Framework, Health and Social Care Information Centre, Information Services Division Scotland. Statistics for Wales, Department of Health, Social Services and Public Safety., 2014-2015.

[33] Holden S, Barnett AH, Peters JR, et al. The incidence of type 2 diabetes in the United Kingdom from 1991 to 2010. Diabetes Obes Metab 2013; 15: 844852

[34] Rhodes E, Prosser L, Hoerger TJ, Lieu T, Ludwig D, Laffel L. Estimated morbidity and mortality in adolescents and young adults diagnosed with type 2 diabetes mellitus. Diabetic Med 2012; 29: 453-463

[35] Wilmot EG, Leggate M, Khan JN, et al. Type 2 diabetes mellitus and obesity in young adults: the extreme phenotype with early cardiovascular dysfunction. Diabetic Med 2014; 31: 794-798

[36] Dart AB, Martens PJ, Rigatto C, Brownell MD, Dean HJ, Sellers EA. Earlier onset of complications in youth with type 2 diabetes. Diabetes Care 2014; 37:

436-443

[37] Report 1: Care Processes and Treatment Targets. National Diabetes Audit, 2015

[38] Scottish Diabetes Survey 2014. Scottish Diabetes Survey Monitoring Group, 2014

[39] Stratton IM, Adler AI, Neil HAW, et al. Association of glycaemia with macrovascular and microvascular complications of type 2 diabetes (UKPDS 35): prospective observational study. BMJ 2000; 321: 405-412

[40] Ali MK, Bullard KM, Saaddine JB, Cowie CC, Imperatore G, Gregg EW. Achievement of goals in US diabetes care, 1999-2010. New Engl J Med 2013; 368: 1613-1624

[41] Fhärm E, Cederholm J, Eliasson B, Gudbjörnsdottir S, Rolandsson O. Time trends in absolute and modifiable coronary heart disease risk in patients with Type 2 diabetes in the Swedish National Diabetes Register (NDR) 2003-2008. Diabetic Med 2012; 29: 198-206

[42] Banegas JR, López-García E, Dallongeville J, et al. Achievement of treatment goals for primary prevention of cardiovascular disease in clinical practice across Europe: the EURIKA study. Eur Heart J 2011; 32: 2143-2152 [43] Stone MA, Charpentier G, Doggen K, et al. Quality of care of people with type 2 diabetes in eight european countries findings from the Guideline Adherence to Enhance Care (GUIDANCE) study. Diabetes Care 2013; 36: 26282638

[44] National Diabetes Audit: executive summary 2009-2010. National Diabetes Audit, 2010

[45] Stettler C, Allemann S, Jüni P, et al. Glycemic control and macrovascular disease in types 1 and 2 diabetes mellitus: meta-analysis of randomized trials. Am Heart J 2006; 152: 27-38 [46] Ray KK, Seshasai SRK, Wijesuriya S, et al. Effect of intensive control of glucose on cardiovascular outcomes and death in patients with diabetes mellitus: a meta-analysis of randomised controlled trials. Lancet 2009; 373: 1765-1772 
[47] Wing RR, Lang W, Wadden TA, et al. Benefits of modest weight loss in improving cardiovascular risk factors in overweight and obese individuals with type 2 diabetes. Diabetes Care 2011; 34: 1481-1486

[48] Turner RC, Cull CA, Frighi V, Holman RR, Group UPDS. Glycemic control with diet, sulfonylurea, metformin, or insulin in patients with type 2 diabetes mellitus: progressive requirement for multiple therapies (UKPDS 49). JAMA 1999; 281: 2005-2012

[49] Smith RJ, Nathan DM, Arslanian SA, Groop L, Rizza RA, Rotter JI. Individualizing therapies in type 2 diabetes mellitus based on patient characteristics: what we know and what we need to know. J Clin Endocr Metab 2010; 95: 1566-1574

[50] Claxton AJ, Cramer J, Pierce C. A systematic review of the associations between dose regimens and medication compliance. Clin Ther 2001; 23: 12961310

[51] Mateo J, Gil - Guillén V, Mateo E, Orozco D, Carbayo J, Merino J.

Multifactorial approach and adherence to prescribed oral medications in patients with type 2 diabetes*. Int J Clin Pract 2006; 60: 422-428

[52] Farmer AJ, Rodgers LR, Lonergan M, et al. Adherence to Oral GlucoseLowering Therapies and Associations With 1-Year HbA1c: A Retrospective Cohort Analysis in a Large Primary Care Database. Diabetes Care 2016; 39: 258263

[53] Karkashian C SD. Adherence to long-term therapies: evidence for action.: World Health Organisation, 2003

[54] Currie CJ, Peyrot M, Morgan CL, et al. The impact of treatment noncompliance on mortality in people with type 2 diabetes. Diabetes Care 2012; 35: $1279-1284$

[55] Han S, Iglay K, Davies MJ, Zhang Q, Radican L. Glycemic effectiveness and medication adherence with fixed-dose combination or coadministered dual therapy of antihyperglycemic regimens: a meta-analysis. Curr Med Res Opin 2012; 28: 969-977

[56] Osterberg L, Blaschke T. Adherence to medication. New Engl J Med 2005; 353: 487-497

[57] Grant R, Adams AS, Trinacty CM, et al. Relationship between patient medication adherence and subsequent clinical inertia in type 2 diabetes glycemic management. Diabetes Care 2007; 30: 807-812

[58] Farmer A, Kinmonth AL, Sutton S. Measuring beliefs about taking hypoglycaemic medication among people with Type 2 diabetes. Diabetic Med 2006; 23: 265-270

[59] Feher M, Vega-Hernandez G, Ye Q, Bogelund M. Potential barriers to insulin intensification in patients with Type 2 diabetes in the UK. Diabetic Med: WILEY-BLACKWELL 111 RIVER ST, HOBOKEN 07030-5774, NJ USA, 2016:155155

[60] Dilla T, Costi M, Boye $\mathrm{K}$, et al. [The impact of obesity in the management and evolution of diabetes mellitus]. Rev Clin Esp 2008; 208: 437-443 
[61] Blak B, Rigney U, Sternhufvud C, Davis J, Hammar N. Weight change and healthcare resource use in English patients with type 2 diabetes mellitus initiating a new diabetes medication class. Int J Clin Pract 2016; 70: 45-55 [62] Wilding JPH BC, Rigney U, Blak B, Beekman W, Emmas CE. . Changes in HbA1c and weight in type 2 diabetes patients initiating dapagliflozin treatment in routine UK primary care. European Association for the Study of Diabetes. Stockholm., 2015

[63] Horton ES, Silberman C, Davis KL, Berria R. Weight loss, glycemic control, and changes in cardiovascular biomarkers in patients with type 2 diabetes receiving incretin therapies or insulin in a large cohort database. Diabetes Care 2010; 33: 1759-1765

[64] Inzucchi S, Bergenstal R, Buse JB, et al. Management of hyperglycaemia in type 2 diabetes: a patient-centered approach. Position statement of the American Diabetes Association (ADA) and the European Association for the Study of Diabetes (EASD). Diabetologia 2012; 55: 1577-1596

[65] Gary TL, Genkinger JM, Guallar E, Peyrot M, Brancati FL. Meta-analysis of randomized educational and behavioral interventions in type 2 diabetes.

Diabetes Educ 2003; 29: 488-501

[66] Deakin T, Cade J, Williams R, Greenwood D. Structured patient education: the Diabetes X - PERT Programme makes a difference. Diabetic Med 2006; 23: 944-954

[67] Khunti K, Gray LJ, Skinner T, et al. Effectiveness of a diabetes education and self management programme (DESMOND) for people with newly diagnosed type 2 diabetes mellitus: three year follow-up of a cluster randomised controlled trial in primary care. 2012:

[68] Pringle M, Stewart-Evans C, Coupland C, Williams I, Allison S, Sterland J. Influences on control in diabetes mellitus: patient, doctor, practice, or delivery of care? BMJ 1993; 306: 630-634

[69] Wallace T, Matthews D. Poor glycaemic control in type 2 diabetes: a conspiracy of disease, suboptimal therapy and attitude. QJM 2000; 93: 369-374 [70] Khunti K, Wolden ML, Thorsted BL, Andersen M, Davies MJ. Clinical Inertia in People With Type 2 Diabetes A retrospective cohort study of more than 80,000 people. Diabetes Care 2013; 36: 3411-3417

[71] Calvert MJ, McManus RJ, Freemantle N. Management of type 2 diabetes with multiple oral hypoglycaemic agents or insulin in primary care:

retrospective cohort study. Br J Gen Pract 2007; 57: 455-460

[72] Paul SK, Klein K, Thorsted BL, Wolden ML, Khunti K. Delay in treatment intensification increases the risks of cardiovascular events in patients with type 2 diabetes. Cardiovasc Diabetol 2015; 14: 1-10

[73] Phillips LS, Branch WT, Cook CB, et al. Clinical inertia. Ann Intern Med 2001; 135: 825-834

[74] Perlin JB, Pogach LM. Improving the outcomes of metabolic conditions: managing momentum to overcome clinical inertia. Ann Intern Med 2006; 144: $525-527$ 
[75] Drass J, Kell S, Osborn M, et al. Diabetes care for Medicare beneficiaries: attitudes and behaviors of primary care physicians. Diabetes Care 1998; 21: 1282-1287

[76] Safford MM, Shewchuk R, Qu H, et al. Reasons for not intensifying medications: differentiating "clinical inertia" from appropriate care. J Gen Intern Med 2007; 22: 1648-1655

[77] Henriksen K, Battles JB, Marks ES, et al. Clinical Inertia and Outpatient Medical Errors. Adv Patient safety 2005:

[78] O'Connor PJ. Improving diabetes care by combating clinical inertia. Health Serv Res 2005; 40: 1854-1861

[79] Zafar A, Davies M, Azhar A, Khunti K. Clinical inertia in management of T2DM. Prim Care Diabetes 2010; 4: 203-207

[80] Khunti K, Gadsby R, Millett C, Majeed A, Davies M. Quality of diabetes care in the UK: comparison of published quality - of - care reports with results of the Quality and Outcomes Framework for Diabetes. Diabetic Med 2007; 24: 14361441

[81] Vaghela P, Ashworth M, Schofield P, Gulliford MC. Population intermediate outcomes of diabetes under pay-for-performance incentives in England from 2004 to 2008. Diabetes Care 2009; 32: 427-429

[82] O'Hare JP, Miller-Jones D, Hanif W, et al. The new NICE guidelines for type 2 diabetes-a critical analysis. Br J Diabetes 2015; 15: 3-7

[83] Miller CD, Ziemer DC, Kolm P, et al. Use of a glucose algorithm to direct diabetes therapy improves $\mathrm{A} 1 \mathrm{C}$ outcomes and defines an approach to assess provider behavior. Diabetes Educ 2006; 32: 533-545

[84] Lester WT, Grant RW, Octo Barnett G, Chueh HC. Randomized Controlled Trial of an Informatics - based Intervention to Increase Statin Prescription for Secondary Prevention of Coronary Disease. J Gen Intern Med 2006; 21: 22-29 [85] Handelsman Y, Bloomgarden Z, Grunberger G. American College of Endocrinology - clinical practice guidelines for developing a diabetes mellitus comprehensive care plan-2015. Endocr Pract 2015; 21: 1-87

[86] Morgan CL, Poole CD, Evans M, Barnett AH, Jenkins-Jones S, Currie CJ. What next after metformin? A retrospective evaluation of the outcome of secondline, glucose-lowering therapies in people with type 2 diabetes. J Clin Endocr Metab 2012; 97: 4605-4612

[87] Bennett WL, Maruthur NM, Singh S, et al. Comparative effectiveness and safety of medications for type 2 diabetes: an update including new drugs and 2drug combinations. Ann Intern Med 2011; 154: 602-613

[88] Vasilakou D, Karagiannis T, Athanasiadou E, et al. Sodium-glucose cotransporter 2 inhibitors for type 2 diabetes: a systematic review and metaanalysis. Ann Intern Med 2013; 159: 262-274

[89] Stenlöf K, Cefalu W, Kim KA, et al. Efficacy and safety of canagliflozin monotherapy in subjects with type 2 diabetes mellitus inadequately controlled with diet and exercise. Diabetes Obes Metab 2013; 15: 372-382 
[90] Wu JH, Foote C, Blomster J, et al. Effects of sodium-glucose cotransporter2 inhibitors on cardiovascular events, death, and major safety outcomes in adults with type 2 diabetes: a systematic review and meta-analysis. Lancet Diabetes Endocrinol 2016:

[91] Zinman B, Wanner C, Lachin JM, et al. Empagliflozin, cardiovascular outcomes, and mortality in type 2 diabetes. New Engl J Med 2015; 373: 21172128

[92] Gall M-A, Nielsen F, Smidt U, Parving H-H. The course of kidney function in type 2 (non-insulin-dependent) diabetic patients with diabetic nephropathy. Diabetologia 1993; 36: 1071-1078

[93] Nosadini R, Velussi M, Brocco E, et al. Course of renal function in type 2 diabetic patients with abnormalities of albumin excretion rate. Diabetes 2000; 49: 476-484

[94] Del Prato S, Nauck M, Duran-Garcia S, et al. Durability of dapagliflozin vs. glipizide as add-on therapies in T2DM inadequately controlled on metformin: 4year data. American Diabetes Association 2013: 21-25

[95] Esposito K, Chiodini P, Maiorino MI, Bellastella G, Capuano A, Giugliano D. Glycaemic durability with dipeptidyl peptidase-4 inhibitors in type 2 diabetes: a systematic review and meta-analysis of long-term randomised controlled trials. BMJ open 2014; 4: e005442

[96] Nordisk N. Top line results: liraglutide effect and action in diabetes: evaluation of cardiovascular outcome results. 2016

[97] Nyeland M, Ploug U, Richards A, et al. Evaluation of the effectiveness of liraglutide and sitagliptin in type 2 diabetes: a retrospective study in UK primary care. Int J Clin Pract 2015; 69: 281-291

[98] Pratley RE, Nauck M, Bailey T, et al. Liraglutide versus sitagliptin for patients with type 2 diabetes who did not have adequate glycaemic control with metformin: a 26-week, randomised, parallel-group, open-label trial. Lancet 2010; 375: 1447-1456

[99] Nathan DM, Buse JB, Kahn SE, et al. Rationale and design of the glycemia reduction approaches in diabetes: a comparative effectiveness study (GRADE). Diabetes Care 2013; 36: 2254-2261

[100] Excellence. NIfC. CG 87 - type 2 diabetes: the management of type 2 diabetes. http://www.nice.org.uk/nicemedia/ live/12165/44320/44320.pdf., 2009 


\section{University Library}

\section{- M M N E R VA A gateway to Melbourne's research publications}

Minerva Access is the Institutional Repository of The University of Melbourne

Author/s:

Bain, SC;Feher, M;Russell-Jones, D;Khunti, K

Title:

Management of type 2 diabetes: the current situation and key opportunities to improve care in the UK.

\section{Date:}

2016-12

\section{Citation:}

Bain, S. C., Feher, M., Russell-Jones, D. \& Khunti, K. (2016). Management of type 2 diabetes: the current situation and key opportunities to improve care in the UK.. Diabetes Obes Metab, 18 (12), pp.1157-1166. https://doi.org/10.1111/dom.12760.

Persistent Link:

http://hdl.handle.net/11343/291722 